\title{
Influence of Dye Content on the Conduction Band Edge of Titania in the Steam-Treated Dye-Dispersing
}

\section{Titania Electrodes}

Rudi Agus Setiawan ${ }^{1}$, Hiromasa Nishikiori* ${ }^{1}$, Nobuaki Tanaka ${ }^{1}$, and Tsuneo Fujii ${ }^{2}$

${ }^{1}$ Department of Environmental Science and Technology, Graduate School of Science and Technology, Shinshu University, 4-17-1 Wakasato, Nagano 380-8553, Japan

${ }^{2}$ Nagano Prefectural Institute of Technology, 813-8 Shimonogo, Ueda, Nagano 386-1211, Japan

*Corresponding author e-mail: nishiki@shinshu-u.ac.jp (Hiromasa Nishikiori) 


\section{ABSTRACT}

The titania and dye-dispersing titania electrodes were prepared by a nitric acid-catalyzed sol-gel process. The dye-dispersing titania contains the dye molecules dispersed on the surface of the individual nanosized titania particles. The photo-cyclic voltammetry (Photo-CV) and photoelectric measurements of the dye-dispersing titania electrodes were conducted in order to clarify the factors changing the conduction band edge of the titania and the open-circuit voltage $\left(\mathrm{V}_{\mathrm{oc}}\right)$ of the electrodes. The remaining nitrate ions caused a negative shift of conduction band edge of the titania of the dye-dispersing titania. The conduction band edge of the titania was shifted in a negative direction in the electrode containing a greater amount of the dye. These results are due to the adsorption of nitrate ions and the dye-titania complex formation on the titania particle surface. The effect of the dye-titania complex formation on the shift in the titania conduction band edge was greater than that of the adsorption of nitrate ions due to strong interaction between the dye and titania through the carboxylate and quinone-like groups of the dye. The shift in the titania conduction band edge corresponded to the change in the $\mathrm{V}_{\mathrm{oc}}$ value.

Keywords: titania; dye; complex formation; conduction band edge; photoelectric conversion; steam treatment 


\section{INTRODUCTION}

Titania photocatalyst is available for sustainable energy production. In recent decades, dye-sensitized solar cells (DSSCs) based on titania have attracted considerable interest as a new potential electric generator due to their low-cost production and simple fabrication process compared to conventional silicon-type solar cells (1-3). Many efforts have been made in order to achieve a high photoelectric conversion efficiency. In a study, more than an $12 \%$ conversion efficiency has been achieved using ruthenium dye complexes as sensitizers (4). Ruthenium dye complexes are known as superior light harvesting and durable materials, but they are very expensive. Therefore, ruthenium dye complexes are not suitable for the large scale production of such solar cells. Many studies have been performed for developing new dyes to replace the ruthenium dye complexes, for example, merocyanine dyes (5), xanthene dyes $(6-10)$, coumarin dyes $(11,12)$, etc. Compared to the ruthenium dye complexes, such organic dyes have two advantages for use in DSSCs. One is the high molar extinction coefficient of the organic dyes due to their oscillator being stronger than those of the metal complexes. The other is that no noble metal such as $\mathrm{Ru}$ is contained in the dye molecules.

This reduces the overall cost of the cell production (13). However, the narrower optical absorption region and higher volatility of such organic dyes than those of the ruthenium dye complexes are the major problems limiting the efficiency of the DSSCs. A combination of some dyes is able to widen the absorption region and a strong bonding of the dyes to the 
titania surface inhibits their volatilization. Such techniques require a new technology to improve the light-harvesting efficiency from the organic dye molecule.

In our studies, we have used xanthene dyes as a sensitizer for the DSSCs. In order to improve the absorption properties of the dyes, we have tried a new method for the preparation of the working electrodes using the dye-dispersing titania. In a conventional method for preparing the working electrodes of the DSSCs, the dyes are adsorbed onto the titania thin films. This method allows the dye to be adsorbed onto only the surface of the relatively large aggregates of the titania particles. In our original investigation, the dye-dispersing titania films were prepared by a simple sol-gel process and used as the working electrodes. This is one step dip-coating process although the conventional method generally consists of at least three processes, i.e., the nanoparticle preparation, film formation, and dye adsorption (1-5). Unlike the conventional method, this method is expected to allow the dye molecules to be dispersed onto the surface of the individual nanosized titania particles at a molecular level. This is important for improving the light absorption efficiency. The dye-dispersing and dye-adsorbing titania films were previously prepared from the systems containing the initial concentration of fluorescein, $1.0 \times 10^{-2} \mathrm{~mol} \mathrm{dm}{ }^{-3}$ (6). The concentration of the dye incorporated in the dye-dispersing titania film, $0.32 \mathrm{~mol} \mathrm{dm}^{-3}$, was about five times higher than that of the dye adsorbed on the conventional film, $6.4 \times 10^{-2} \mathrm{~mol} \mathrm{dm}^{-3}$. The other advantage is the high contact area between the dye and titania. This can improve the 
dye-titania interaction and electron injection from the individual dye into the titania.

In our previous study, the steam treatment of the dye-dispersing titania films remarkably improved the photoelectric conversion efficiency due not only to the crystallization of the titania, but also to the formation of the dye-titanium LMCT complex on the titania surface $(6,9,10)$. The dye-titania complex formation by the steam treatment was revealed by FTIR and photoelectric measurements. The FTIR spectra of the dye-dispersing titania samples indicated that the chelate complex formation increased the short circuit current and open circuit voltage $\left(\mathrm{V}_{\mathrm{oc}}\right)(6,9)$. Based on the relationship between the increase in the amount of the dye-titania complex and the $\mathrm{V}_{\mathrm{oc}}$ value, we concluded that the dye-titania complex formation significantly affected the change in the conduction band edge of the titania.

It is important to control the conduction band potential, on which the available energy depends. However, the mechanism for the fact that the dye-titania complex formation changes the conduction band edge of the titania and the $\mathrm{V}_{\text {oc }}$ value of the titania electrode, is still unclear. In this study, we have tried to control the dye-titania complex formation by changing the dye content in the electrodes.

Actually, there are many methods used for the determination of the position of the conduction band edge. The most common method is the Mott-Schottky plot resulting from the measurement of impedance (14). Cyclic voltammetry (CV) is also one of methods which can determine the band levels of a semiconductor (15-17). Another common method for the 
determination of the position of the conduction band edge is the measurement of the potential dependence of the photocurrent called the "photocurrent onset measurement" $(18,19)$. In this study, the measurement of the photocurrent onset determined by CV during light irradiation for the band-gap excitation of the titania (Photo-CV) was conducted in order to estimate the shift in the conduction band edge of the titania in each electrode.

The photoelectric measurements for the dye-dispersing titania electrodes were also conducted in order to clarify the relationship between the conduction band edge of the titania and the $\mathrm{V}_{\mathrm{oc}}$ value.

\section{MATERIALS AND METHODS}

Materials. Titanium tetraisopropoxide, ethanol, fluorescein, hydrochloric acid, nitric acid, diethylene glycol, acetonitrile, tetrabutylammonium perchlorate, iodine, sodium hydroxide, lithium iodide, lithium nitrate, sodium nitrate, and potassium nitrate (Wako, $\mathrm{S}$ or reagent grade) were used without further purification. Water was ion-exchanged and distilled.

Glass plates coated with the transparent ITO electrode (AGC Fabritech) were soaked in

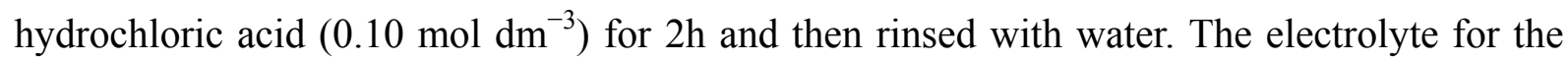
Photo-CV consisted of an acetonitrile solution of $0.10 \mathrm{~mol} \mathrm{dm}^{-3}$ tetrabutylammonium perchlorate. The electrolyte for the photoelectric measurement consisted of a diethylene glycol solution of iodine $\left(5.0 \times 10^{-2} \mathrm{~mol} \mathrm{dm}^{-3}\right)$ and lithium iodide $\left(0.50 \mathrm{~mol} \mathrm{dm}{ }^{-3}\right)$. 
Preparation of electrodes. The titania sols containing titanium alkoxide, nitric acid, pure water, ethanol, and fluorescein, in which the fluorescein concentrations were $0,1.0 \times 10^{-3}$, $3.0 \times 10^{-3}$, and $1.0 \times 10^{-2} \mathrm{~mol} \mathrm{dm}{ }^{-3}$, were labeled S0, S1, S2, and S3, respectively. Detailed methods for the sample preparation are described in a previous paper (6).

The working electrodes for Photo-CV were prepared by the following steps: (1) The glass plate with the ITO electrode was dip-coated once with $\mathrm{S} 0$ and then heated at $500^{\circ} \mathrm{C}$ for $30 \mathrm{~min}$ in order to form the crystalline titania as a substrate layer. This layer plays the role as a bonding layer between the dye-dispersing titania layer and the ITO layer. (2) This electrode was dip-coated 10 times with S0, S1, S2, or S3 and then steam-treated for $120 \mathrm{~min}$ and labeled WE-S0, WE-S1, WE-S2, and WE-S3, respectively. The 10-times coating was for obtaining as strong photocurrent signal as possible. In order to clarify the relationship between the amount of the nitrate ions adsorbed on the titania surface and the shift in the conduction band edge of the titania, the WE-S0 electrodes were treated with an aqueous solution of sodium hydroxide for 20 and $40 \mathrm{~min}$, then with an aqueous solution of lithium nitrate, sodium nitrate, or potassium nitrate for $40 \mathrm{~min}$. These were used as the working electrodes for the Photo-CV. The glass plates without ITO were also coated with the dye-dispersing titania sols in order to obtain the XRD patterns of the titania.

The working electrodes for the photoelectric measurements were prepared by the following steps: (1) The ITO electrode was dip-coated 3 times with S0 and then heated at $500^{\circ} \mathrm{C}$ for 30 
min in order to form the crystalline titania. This layer plays the role as a blocking layer in order to suppress the charge recombination at the interface between the dye-dispersing titania layer and the ITO layer (20-22). The 3-times coating provided the best performance as the blocking layer. (2) This electrode was dip-coated 5 times with S0, S1, S2, or S3 and then steam-treated for 120 min and labeled PE-S0, PE-S1, PE-S2, and PE-S3, respectively. The 5-times coating provided the best performance of the cells under the present conditions.

Measurements. The crystalline phase of the film samples was determined using an X-ray diffractometer (Rigaku SmartLab). The UV-visible absorption spectra of the prepared electrode samples were observed using a UV-visible-near IR spectrophotometer (Shimadzu UV-3150). A $340 \mathrm{~nm}$ light $\left(4.7 \mathrm{~mW} \mathrm{~cm}\right.$ cm $\left.^{-2}\right)$ was obtained from a fluorescence spectrophotometer (Shimadzu RF-5300) with a 150 W Xe short arc lamp (Ushio UXL-155). The area of the irradiated electrode was $0.4 \mathrm{~cm}^{2}$ although that of the whole electrode was 10 $\mathrm{cm}^{2}$. During the light irradiation, the cyclic voltammogram of each electrode was measured by a potentiostat (Hokuto Denko HSV-100) in a three-electrode cell, assembled with a platinum counter electrode, an $\mathrm{Ag} / \mathrm{AgCl}$ in saturated $\mathrm{KCl}\left(3.4 \mathrm{~mol} \mathrm{dm}^{-3}\right)$ electrolyte as the reference electrode, and the working electrode. The applied voltage was swept from -1.0 to $0 \mathrm{~V}$ at 10 $\mathrm{mV} \mathrm{s}^{-1}$ in order to estimate the oxidation potential of the titania conduction band with the excited electrons. The electrolyte was treated with bubbling nitrogen gas for about $30 \mathrm{~min}$ before the measurements. The dark current was also measured under the same conditions. The 
oxidation current was obtained by subtracting the dark current from the photocurrent.

The iodine-based electrolyte was allowed to soak into the space between the electrode sample and the counter Pt electrode. The $J$ - $V$ curves of the electrodes were measured by the potentiostat during visible light $\left(0.40 \mathrm{~W} \mathrm{~cm}^{-2}\right)$ irradiation at a wavelength longer than $400 \mathrm{~nm}$ emitted by the $150 \mathrm{~W}$ Xe short arc lamp using a sharp cutoff filter. For the $J-V$ measurements of WE-S0, no cutoff filter was used due to the absence of dye in the electrode.

The DC electrical resistance of the ITO electrode was measured using a digital multimeter (ADCMT 7461A). The resistivity values for the ITO electrodes unheated and heated at $500^{\circ} \mathrm{C}$ for $30 \mathrm{~min}$ were $2.0 \times 10^{-4}$ and $4.9 \times 10^{-4} \Omega \mathrm{cm}$, respectively. The resistivity of the heated ITO was low enough to determine the electric properties of the electrode samples.

The dye powder and the flakes of the dye-dispersing titania film samples were pressed in $\mathrm{KBr}$ pellets and their IR spectra were obtained using an FTIR spectrophotometer (Shimadzu IR Prestige-21). The amounts of the dye and nitrate ions adsorbed on the titania surface were estimated from the UV-vis absorption and IR spectra, respectively.

\section{RESULTS AND DISCUSSION}

\section{Influence of the dye content on conduction band edge of titania}

We conducted the Photo-CV in order to determine the shift in the conduction band edge of the titania in each electrode. The Photo-CV curves for the dye-dispersing titania electrodes were 
obtained as a function of the dye content and their oxidation currents are shown in Figure 1. The three cycles of the Photo-CV curves of WE-S0 are inserted in Figure 1. A peak at $-0.63 \mathrm{~V}$ was observed in the first cycle of the Photo-CV of WE-S0, and the peak shifted to a negative voltage after the first cycle. This phenomenon was observed in all the electrode samples. The initial peak can be assigned to the reduction of oxygen adsorbed on the titania surface as shown by Reinhardt et al (23).

In this study, the titania conduction band edge was estimated from the onset potential of the oxidation current of the third-cyclic Photo-CV curve of each electrode. The values for the electrode with different dye contents are summarized in Table 1. The onset potential of the oxidation photocurrent was more negative in the electrode containing a greater amount of the dye, indicating that the conduction band edge of the titania shifted to a negative value with the dye content. The conduction band edge of WE-S3 was more negative by about $70 \mathrm{mV}$ than that of WE-S0.

\section{Figure 1}

\section{Table 1}

This result agreed with our prediction. It was reported that xanthene dye molecules formed a chelated complex with the titanium species on the titania surface in the dye-titania systems (24-26). We predicted that the negative surface electronic density of the titania would increase with an increase in the amount of the dye-titania complex depending on the dye content in the 
electrode, which would result in a shift in the conduction band into a more negative direction. In our previous study, we also concluded that the steam treatment, which promoted the dye-titania complex formation, caused a negative shift in the conduction band edge of the titania (6). During the treatment, active gaseous water promoted the hydrolysis of the titanium species and enhanced their reactivity. The titanium chelation of the fluorescein species was promoted in the narrow spaces of the titania networks.

Our question is whether there is another factor shifting the conduction band edge of the titania other than the dye-titania complex formation. Actually, there can be many factors changing the conduction band edge of the titania. An adsorbent on the titania surface significantly changed the conduction band edge $(27,28)$. The particle size $(29)$, the surface protonation due to acid treatment (30-32), and the dipole moment of the dye adsorbed on the titania $(33,34)$ are also the factors which shift the conduction band edge of the titania. Therefore, further investigation is required in order to clarify this problem.

The XRD analysis and SEM observations of the electrodes were conducted in order to examine the influence of the dye content on the particle size. Figure 2 shows the XRD patterns of the electrodes containing the different amounts of the dye. The average crystallite size of the crystalline particles of each electrode was estimated from their full width at half-maximum of the $25.3^{\circ}$ peak using Sherrer's equation, $D=0.9 \lambda / \beta \cos \theta$. The average crystallite size of the titania was about $5 \mathrm{~nm}$ for each electrode and was not significantly 
different between the electrodes.

\section{Figure 2}

Figure 3 shows an SEM image of each electrode. The particle size in the electrode was about $10-20 \mathrm{~nm}$ and not significantly changed by the dye content. Based on this result, we suggested that the possibility of the influence by a quantum size effect in this case is very low. Another factor, such as the surface protonation, cannot be the reason for such a change because we did not observe any significant change in $\mathrm{pH}$ even in the titania sol containing a higher amount of the dye.

\section{Figure 3}

Pandey et al. reported that the difference in the dipole moments between the dye and the titania induces a negative or positive shift in the surface potential. The positive dipoles, i.e., dipole moments pointed toward the outer surface of the dyes adsorbed on the titania surface, were formed by most of the organic dyes at the titania/dye interface and shifted the titania conduction band edge in a positive direction (3). Our result is opposite to that of Pandey et al., indicating that the hypothesis of Pandey et al. cannot explain the shift in the conduction band edge of the dye-dispersing titania. We presume that the dipole moment factor of the dye has a small effect. The dye molecules did not clearly exhibit an anisotropic property because the dye molecules were tightly encapsulated in the narrow spaces surrounded by the titania particles. However, further investigation is needed in order to discuss this problem in another 
study.

The most likely reason for the change in the conduction band edge vs. the dye content except for the dye-titania complex formation is an adsorbent on the titania surface. The FTIR measurement was conducted in order to identify the species adsorbed on the titania surface of the electrodes. Figure 4 shows the FTIR spectrum of the dye-dispersing titania electrode as a function of the dye content. For comparison, the FTIR spectrum of fluorescein powder is also inserted in Figure 4. The peaks of the carboxyl $\mathrm{C}=\mathrm{O}$ stretching vibration and the carboxylate $\mathrm{COO}^{-}$antisymmetric and symmetric stetching vibrations were observed at 1710,1597 , and $1391 \mathrm{~cm}^{-1}$ for the fluorescein powder, respectively. In addition, the band at $1490 \mathrm{~cm}^{-1}$ was assigned to the quinone-like $\mathrm{C}=\mathrm{O}$ stretching vibration. In WE-S3, the peaks at 1620,1585 , 1470 , and $1385 \mathrm{~cm}^{-1}$ were assigned to the absorbed water on the titania surface, the carboxylate $\mathrm{COO}^{-}$antisymmetric stretching and the quinone-like $\mathrm{C}=\mathrm{O}$ stretching vibrations of fluorescein (6), and the adsorbed $\mathrm{NO}_{3}^{-}$(35), respectively. The carboxylate $\mathrm{COO}^{-}$ antisymmetric and quinone-like $\mathrm{C}=\mathrm{O}$ stretching vibration peaks were shifted to a low wavenumber compared to those observed in the fluorescein powder due to the interaction between the functional groups and the titanium species of the titania. The carboxyl group of fluorescein was transformed to the carboxylate and formed a chelated complex with the titanium species (6). The peaks at 1620 and $1385 \mathrm{~cm}^{-1}$ were also observed in WE-S0. The nitrate ion still remained on the electrodes even after the steam treatment. 


\section{Figure 4}

In order to clarify relationship between the amount of the adsorbed nitrate ions and the shift in the conduction band edge of the titania, the FTIR analysis and Photo-CV of the titania electrode were conducted before and after the sodium hydroxide solution treatment. Figure 5 shows the FTIR spectra of each electrode measured before and after the sodium hydroxide treatment in order to confirm the nitrate ion remaining on the titania surface. The intensity of the peak at $1385 \mathrm{~cm}^{-1}$, assigned to nitrate ion, decreased with the sodium hydroxide treatment, and then the peak completely disappeared in the titania electrode after $40 \mathrm{~min}$.

\section{Figure 5}

Figure 6 shown the Photo-CV curves of the titania electrodes before and after the sodium hydroxide treatment, then after the lithium nitrate, sodium nitrate, or potassium nitrate treatment. The onset potentials of the oxidation photocurrents of each electrode are summarized in Table 2. The onset potential of the oxidation photocurrent of the electrode was shifted in a positive direction by about 30 and $50 \mathrm{mV}$ after the 20- and 40-min sodium hydroxide treatments, respectively. This result indicated that the conduction band edge of the titania was shifted in a positive direction due to the decreasing amounts of nitrate ions adsorbed on the electrode. The onset potential value was recovered after the lithium nitrate, sodium nitrate, or potassium nitrate treatment because the nitrate ions were adsorbed on the titania surface independent of the cations. This result indicated that the titania surface had a 
positive charge under the present conditions.

\section{Figure 6}

\section{Table 2}

It has not been concluded which factor, the dye-titania complex formation or nitrate ion adsorption, has a greater effect on the changes in the conduction band edge of the titania. The initial amount of nitrate ions in the dye-containing titania sol was 10 -fold greater than that of the dye. The relative amounts of the dye molecules and nitrate ions adsorbed on the dye-titania gel electrode just after the preparation before steam treatment are assumed to be the same as those in the dye-containing titania sol. Based on this assumption, we calculated the approximate amount of the dye molecules and nitrate ions in the dye-dispersing titania electrode WE-S3 before and after the steam treatment. The UV-vis and FTIR spectra were obtained in order to estimate the amounts of the dye molecules and nitrate ions, respectively.

Figure 7 shows the UV-vis and FTIR spectra of WE-S3 before and after the 120-min steam treatment. In the UV-vis spectra, the absorbance of the band at 470-480 nm assigned to the dye absorption decreased by $50 \%$ after the steam treatment. The absorbance at the peak assigned to the nitrate ion decreased by two-thirds as shown in the FTIR spectra. As the amounts of the dye molecules and nitrate ions were assumed to be 1 and 10, respectively, in the electrode before the steam treatment, they should be 0.5 and 3.3 , respectively, after the steam treatment. Based on this approximate calculation, we concluded that the amount of 
nitrate ions remaining on the electrode was 6.6 times greater than that of the dye although the negative shift in the conduction band edge was $70 \mathrm{mV}$ and $50 \mathrm{mV}$ by the amount of the dye and nitrate ion, respectively. This result indicated that the effect of the dye-titania complex formation on the shift of the titania conduction band edge was greater than that of the nitrate ion adsorption due to strong interaction between the dye and titania through the carboxylate and quinone-like groups of the dye $(6,9)$.

\section{Figure 7}

\section{Relationship between the dye and nitrate ions on the titania surface}

We confirmed that the dye-titania complex formation and nitrate ion adsorption shifted the conduction band edge of the titania in a negative direction. We will now discuss a schematic diagram of the relationship between the dye-titania complex formation and nitrate ion adsorption on the titania surface. Our attention focused on the change in the dye-titania interaction found in the $\mathrm{COO}^{-}$peak wavenumber and the change in the amount of the nitrate ion adsorbed on the titania surface vs. the dye content as shown in Figure 4. The relative intensity of the peak at $1385 \mathrm{~cm}^{-1}$ assigned to $\mathrm{NO}_{3}{ }^{-}$decreased with an increase in the dye amount. On the other hand, the amount of the complex should increase with the dye content. Based on these results, we suggested that the substitution of the dye molecules for the nitrate ions caused by the dye-titania complex formation as shown in Figure 8, which resulted in the greater negative shift in the titania conduction band edge with the higher dye content. Our 
previous study indicated that, in the hydrochloric acid-catalyzed sol-gel systems, the fluorescein molecules were adsorbed on the titania surface covered with many hydroxide groups before and after the steam treatment because hydrochloric acid evaporated during the film preparation. In the sulfuric acid systems, the fluorescein molecules were adsorbed on the titania surface covered with many sulfate ions before the steam treatment, and then desorbed into the water phase during the steam treatment because the sulfate ions remained on the titania surface (36).

\section{Figure 8}

\section{Influence of the dye content on photoelectric conversion properties of the dye-dispersing}

\section{titania electrode}

The relationship between the shift in the conduction band edge and the change in $\mathrm{V}_{\mathrm{oc}}$ with the dye content will now be described. Before this, the influence of the dye content on the absorption spectrum of each electrode was investigated. Figure 9 shows the absorption spectra of the dye-dispersing titania electrodes observed as a function of the dye content. All the electrodes exhibited broad absorption spectra ranging from $420 \mathrm{~nm}$ to $550 \mathrm{~nm}$, and the absorption peaks are located around $480-490 \mathrm{~nm}$, indicating that the dye-titania complex was formed on each electrode. The absorbance of the electrode increased with an increase in the dye content, and there is a slight difference in the absorption peaks of each electrode. This result indicated that the dye species in the dye-titania complex was not changed by the dye 
content. Based on the FTIR and UV-vis absorption spectra, the dye-titania complex species consisted of the anion (at around $470 \mathrm{~nm}$ ) or the dianion species (at around $490 \mathrm{~nm})(37,38)$.

\section{Figure 9}

The $J-V$ curves of each electrode are shown in Figure 10, and their properties are summarized in Table 3. The $\mathrm{V}_{\mathrm{oc}}$ of the dye-dispersing titania electrode increased with the dye content. The $\mathrm{V}_{\mathrm{oc}}$ value of the PE-S3 electrode was higher by about $70 \mathrm{mV}$ than that of the PE-S0 electrode. This value was equal to the difference between their conduction band edges, about $70 \mathrm{mV}$.

\section{Figure 10}

\section{Table 3}

$\mathrm{V}_{\mathrm{oc}}$ is defined as the voltage difference between the electrolyte redox potential $\left(\mathrm{E}_{\mathrm{redox}} / \mathrm{q}\right)$ and the quasi-Fermi potential of electrons $\left(\mathrm{E}_{\mathrm{F}, \mathrm{n}} / \mathrm{q}\right)$ in the titania. $\mathrm{E}_{\mathrm{F}, \mathrm{n}}$ is determined by the potential of the conduction band edge and the electron density in the titania. $\mathrm{V}_{\mathrm{oc}}$ is described as

$$
\mathrm{V}_{\mathrm{oc}}=\frac{\mathrm{E}_{\mathrm{CB}}}{\mathrm{q}}+\beta \frac{\mathrm{kT}}{\mathrm{q}} \ln \left(\frac{\mathrm{n}}{\mathrm{N}_{\mathrm{CB}}}\right)-\frac{\mathrm{E}_{\text {redox }}}{\mathrm{q}}
$$

where $\mathrm{E}_{\mathrm{CB}}$ is the energy level of the conduction band edge, $\mathrm{N}_{\mathrm{CB}}$ is the total number of conduction band states in the semiconductor, $\mathrm{n}$ is the number of electrons in titania and $\mathrm{q}$ is the elementary charge of the electron. $\beta$ is the defect condition in the porous titania. For the ideal case, i.e., a defect-free semiconductor material, $\beta=1$. From equation 1 , the level of the 
conduction band edge of the titania and the concentration of electrons in the titania are two important factors determining $\mathrm{V}_{\mathrm{oc}}$ because $\mathrm{E}_{\mathrm{redox}}$ is assumed to be constant. The electron density in the titania films is determined by the balance between the electron injection and back electron transport $(40,41)$. Based on these results, the $\mathrm{V}_{\text {oc }}$ value mainly depends on the conduction band edge rather than the electron density in the conduction band. We suggested that the dye molecules and nitrate ions in the dye-dispersing titania slightly affected the electron density in the conduction band.

The values shown in Table 3 were much lower than those of the general dye-sensitized solar cells because the very thin titania films were used for the semiconductor layers in the present electrodes in order to obtain their exact absorbance and quantum efficiency. The IPCE at $500 \mathrm{~nm}, 17 \%$, and internal energy conversion efficiency, 1.1\%, were obtained using a thicker titania electrode coated with such a fluorescein-dispersing titania film in a previous study (42). Furthermore, the DSSCs using crystalline titania electrodes coated with N3 dye-dispersing titania exhibited an IPCE at $520 \mathrm{~nm}, 75 \%$, and an internal energy conversion efficiency, $1.1 \%$ (43).

\section{CONCLUSIONS}

The titania and dye-dispersing titania electrodes were prepared by a nitric acid-catalyzed sol-gel process. We investigated the influence of the amounts of the dye and remaining nitrate 
ions in the dye-dispersing titania electrode on the change in the conduction band edge of the titania and the $\mathrm{V}_{\mathrm{oc}}$ of the electrode.

The Photo-CV curves of the electrodes indicated that the conduction band edge of the titania was more negative in the electrode containing a higher amount of the dye. Compared to the dye-free electrode WE-S0, the conduction band edge of the dye-dispersing electrode WE-S3 was shifted by about $70 \mathrm{mV}$ in the negative direction. The FTIR spectra of the steam-treated dye-dispersing titania electrode showed that the dye-titania complex was formed and nitrate ions remained on the electrode. The Photo-CV curves of the titania electrode before and after the sodium hydroxide treatment showed that the conduction band edge of the titania was shifted by about $50 \mathrm{mV}$ in the positive direction due to desorption of the nitrate ions. This result indicated that the nitrate ions adsorbed on the titania electrode caused a negative shift in the conduction band edge due to their negative charge. The substitution of the dye molecules for the nitrate ions on the titania surface was caused by the dye-titania complex formation. Consequently, the conduction band edge was more negative in the electrode containing a higher amount of the dye. As we predicted, the dye-titania complex formation also significantly affected the conduction band edge of the titania. Our investigation showed that the effect of the dye-titania complex formation on the shift in the titania conduction band edge $(70 \mathrm{mV})$ was greater than that of the nitrate ion adsorption $(50 \mathrm{mV})$ due to a strong interaction between the dye and titania through the carboxylate and quinone-like 
groups of the dye. The shift in the titania conduction band edge corresponded to the change in the $\mathrm{V}_{\text {oc }}$ value $(70 \mathrm{mV})$.

Acknowledgements This work has been supported by JSPS KAKENHI Grant Number 24550153.

\section{REFERENCES}

1 Hagberg, D. P., T. Edvinsson, T. Marinado, G. Boschloo, A. Hagfeldt and L. Sun (2006) Organic chromopore for dye-sensitized nanostructured solar cells. Chem. Commun. 21, $2245-2247$.

2 Xia, J. and S. Yanagida (2011) Strategy to improve the performance of dye-sensitized solar cells: interface engineering principle. Sol. Energy 85, 3143-3159.

3 Pandey, S. S., S. Sakaguchi, Y. Yamaguchi and S. Hayase (2010) Influence of nature of surface dipoles on observed photovoltage in dye-sensitized solar cells as probed by surface potential measurement. Org. Electron. 11, 419-426.

4 Kinoshita, T., J. T. Dy, S. Uchida, T. Kubo and H. Segawa (2013) Wideband dye-sensitized solar cells employing a phosphine-coordinated ruthenium sensitizer. Nature Photonics 7, 535-539.

5 Khazraji, A. C., S. Hotchandani, S. Das and P. V. Kamat (1999) Controlling dye (merocyanine-540) aggregation on nanostructured $\mathrm{TiO}_{2}$ films. an organized assembly 
approach for enhancing the efficiency of photosensitization. J. Phys. Chem. B 103, 4693-4700.

6 Nishikiori, H., Y. Uesugi, S. Takami, R. A. Setiawan, T. Fujii, W. Qian and M. A. El-Sayed (2011) Influence of steam treatment on dye-titania complex formation and photoelectric conversion property of dye-doped titania gel. J. Phys. Chem. C 115, 2880-2887.

7 Nishikiori, H., W. Qian, M. A. El-Sayed, N. Tanaka and T. Fujii (2007) Change in titania structure from amorphousness to crystalline increasing photoinduced electron-transfer rate in dye-titania system. J. Phys. Chem. C 111, 9008-9011.

8 Nishikiori, H., N. Tanaka, T. Kitsui and T. Fujii (2006) Photocurrent observed in dye-doped titania gel. J. Photochem. Photobiol., A 179, 125-129.

9 Setiawan, R. A., H. Nishikiori, Y. Uesugi, K. Miyashita, M. A. El-Sayed and T. Fujii (2013) Electron transfer process in fluorescein-dispersing titania gel films observed by time-resolved fluorescene spectroscopy. J. Phys. Chem. C 117, 10308-10314.

10 Nishikiori, H., Y. Uesugi, N. Tanaka and T. Fujii (2009) Photo-electric conversion in dye-doped nanocrystalline titania films. J. Photochem. Photobiol., A 207, 204-208.

11 Wang, Z. S., Y. Cui, K. Hara, Y. Dan-oh, C. Kasada and A. Shinpo (2007) A high-light-harvesting-efficiency coumarin dye for stable dye-sensitized solar cells. $A d v$. Mater. 19, 1138-1141.

12 Hara, K., Y. Dan-oh, C. Kasada, Y. Ohga, A. Shinpo, S. Suga, K. Sayama and H. Arakawa 
(2004) Effect of additives on the photovoltaic performance of coumarin-dye-sensitized nanocrystalline $\mathrm{TiO}_{2}$ solar cells. Langmuir 20, 4205-4210.

13 Wang, Z. S., K. Hara, Y. Dan-oh, C. Kasada, Y. Ohga, A. Shinpo, S. Suga, H. Arakawa and H. Sugihara (2005) Photophysical and (photo)electrochemical properties of a coumarin dye. J. Phys. Chem. B 109, 3907-3914.

14 Katz, M. J., M. J. D. Vermeer, O. K. Farha, M. J. Pellin and J. T. Hupp (2013) Effects of adsorbed pyridine derivatives and ultrathin atomic-layer-deposited alumina coatings on the conduction band-edge energy of $\mathrm{TiO}_{2}$ and on redox-shuttle-derived dark currents. Langmuir 29, 806-814.

15 Inamdar, S. N., P. P. Ingole and S. K. Haram (2008) Determination of band structure parameters and the quasi-particle gap of CdSe quantum dots by cyclic voltammetry. Chemphyschem 9, 2574-2579.

16 Haram, S. K., B. N. Quinn and A. J. Bard (2001) Electrochemistry of CdS nanoparticles: a correlation between optical and electrochemical band gaps. J. Am. Chem. Soc. 123, $8860-8861$.

17 Haram, S. K., A. Kshirsagar, Y. G. Gurajathi, P. P. Ingole, O. A. Nene, G. B. Markad and S. P. Nanavati (2011) Quantum confinement in CdTe quantum dots: investigation through cyclic voltammetry supported by density functional theory (DFT). J. Phys. Chem. C 115, 6243-6249. 
18 Bolts, J. M. and M. S. Wrighton (1976) Correlation of photocurrent-voltage curves with flat-band potential for stable photoelectrodes for the photoelectrolysis of water. J. Phys.

Chem. 80, 2641-2645.

19 Radecka, M., M. Rekas, A. Trenczek-Zajac and K. Zakrzewska (2008) Importance of the band gap energy and flat band potential for application of modified $\mathrm{TiO}_{2}$ photoanodes in water photolysis. J. Power Sources 181, 46-55.

20 Cameron, P. J. and L. M. Peter (2003) Characterization of titanium dioxide blocking layers in dye-sensitized nanocrystalline solar cells. J. Phys. Chem. B 107, 14394-14400.

21 Patrocinio, A. O. T., L. G. Paterno and N. Y. Murakami Iha (2009) Layer-by-layer $\mathrm{TiO}_{2}$ films as efficienct blocking layers in dye-sensitized solar cells. J. Photochem. Photobiol., A 205, 23-27.

22 Hart, J. N., D. Menzies, Y. B. Cheng, G. P. Simon and L. Spiccia (2006) $\mathrm{TiO}_{2}$ sol-gel blocking layers for dye-sensitized solar cells. C. R. Chimie 9, 622-626.

23 Reinhardt, D., S. Krieck and S. Meyer (2006) Special titanium dioxide layers and their electrochemical behavior. Electrochim. acta 52, 825-830.

24 Hilgendorff, M. and V. Sundström (1998) Dynamics of electron injection and recombination of dye-sensitized $\mathrm{TiO}_{2}$ particles. J. Phys. Chem. B 102, 10505-10514.

25 Ramakrishna, G. and H. N. Ghosh (2001) Emission from the charge transfer state of xanthene dye-sensitized $\mathrm{TiO}_{2}$ nanopaticles: a new approach to determining back electron 
transfer rate and verifying the Marcus inverted regime. J. Phys. Chem. B 105, 7000-7008.

26 El Mekkawai, D. and M. S. A. Abdel-Mottaleb (2005) The interaction and photostability of some xanthenes and selected azo sensitizing dyes with $\mathrm{TiO}_{2}$ nanoparticles. Int. J. Photoenergy 7, 95-101.

27 Du, L., A. Furube, K. Hara, R. Katoh and M. Tachiya (2010) Mechanism of particle size effect on electron injection efficiency in ruthenium dye-sensitized $\mathrm{TiO}_{2}$ nanoparticle films. J. Phys. Chem. C 114, 8135-8143.

28 Ren, X., Q. Feng, G. Zhou, C. H. Huang and Z. S. Wang (2010) Effect of cations in coadsorbate on charge recombination and conduction band edge movement in dye-sensitized solar cells. J. Phys. Chem. C 114, 7190-7195.

29 Neale, N. R., N. Kopidakis, J. V. de Lagemaat, M. Grätzel and A. J. Frank (2005) Effect of a coadsorbent on the performance of dye-sensitized $\mathrm{TiO}_{2}$ solar cells: shielding versus band-edge movement. J. Phys. Chem. B 109, 23183-23189.

30 Wang, Z. S., T. Yamaguchi, H. Sugihara and H. Arakawa (2005) Significant efficiency improvement of the black dye-sensitized solar cell through protonation of $\mathrm{TiO}_{2}$ films. Langmuir 21, 4272-4276.

31 Park, K. H., E. M. Jin, H. B. Gu, S. E. Shim and C. K. Hong (2009) Effects of $\mathrm{HNO}_{3}$ treatment of $\mathrm{TiO}_{2}$ nanoparticles on the photovoltaic properties of dye-sensitized solar cells. Mater. Lett. 63, 2208-2211. 
32 Hao, S., J. Wu, L. Fan, Y. Huang, J. Lin and Y. Wei (2004) The influence of acid treatment of $\mathrm{TiO}_{2}$ porous film electrode on photoelectric performance of dye-sensitized solar cell. Sol. Energy 76, 745-750.

33 Liu, B., X. Li, M. Liu, Z. Ning, Q. Zhang, C. Li, K. Mülen and W. Zhu (2012) Photovoltaic performance of solid-state DSSCs sensitized with organic isophorone dyes: effect of dye-loaded amount and dipole moment. Dyes and Pigments 94, 23-27.

34 Cappel, U. B., S. Plogmaker, E. M. J. Johansson, A. Hagfeldt, G. Boschloo and H. Rensmo (2011) Energy alignment and surface dipoles of rylene dyes adsorbed to $\mathrm{TiO}_{2}$ nanoparticles. Phys. Chem. Chem. Phys. 13, 14767-14774.

35 Musić, S., M. Gotić, M. Ivanda, S. Popović, A. Turković, R. Trojko, A. Sekulić and K. Furić (1997) Chemical and microstructural properties of $\mathrm{TiO}_{2}$ synthesized by sol-gel procedure. Mater. Sci. Eng. B 47, 33-40.

36 Nishikiori, H., R. A. Setiawan, K. Miyashita, K. Teshima and T. Fujii (2014) Influences of acid on molecular forms of fluorescein and photoinduced electron transfer in fluorescein-dispersing sol-gel titania films. Photochem. Photobiol. DOI: 10.1111/php.12254.

37 Sjöback, R., J. Nygren and M. Kubista (1995) Absorption and fluorescence properties of fluorescein. Spectrochim. Acta A 51, L7-L21.

38 Fujii, T., A. Ishii, Y. Kurihara and M. Anpo (1993) Multiple fluorescence spectra of 
fluorescein molecules encapsulated in the silica xerogel prepared by the sol-gel reaction. Res. Chem. Intermed. 19, 333-342.

39 Marinado, T., K. Nonomura, J. Nissfolk, M. K. Karlsson, D. P. Hagberg, L. Sun, S. Mori and A. Hagfeldt (2010) How the nature of triphenylamine-polyene dyes in dye-sensitized solar cells affects the open-circuit voltage and electron lifetimes. Langmuir 26, 2592-2598.

40 Liang, Y., B. Peng and J. Chen (2010) Correlation dye adsorption behavior with the open-circuit voltage of triphenylamine-based dye-sensitized solar cells. J. Phys. Chem. C 114, 10992-10998.

41 Miyashita, M., K. Sunahara, T. Nishikawa, Y. Uemura, N. Koumura, K. Hara, A. Mori, T. Abe, E. Suzuki and S. Mori (2008) Interfacial electron-transfer kinetics in metal-free organic dye-sensitized solar cells: combined effects of molecular structure of dyes and electrolyte. J. Am. Chem. Soc. 130, 17874-17881.

42 Nishikiori, H., Y. Uesugi, R. A. Setiawan and K. Teshima, (2012) Photoelectric conversion properties of dye-sensitized solar cell electrodes with dye-dispersing titania layers, J. Soc. Inorg. Mater. Jpn. 19, 237-242.

43 Nishikiori, H., Y. Uesugi, R. A. Setiawan, T. Fujii, W. Qian and M. A. El-Sayed. (2012) Photoelectric conversion properties of dye-sensitized solar cells using dye-dispersing titania, J. Phys. Chem. C. 116, 4848-4854. 
Table 1 The onset potential of the oxidation current of the titania electrode (WE-S0) and the dye-dispersing titania electrodes with different dye contents (WE-S1, WE-S2, and WE-S3).

\begin{tabular}{cc}
\hline Electrode & $\begin{array}{c}\text { Onset Potential/ V } \\
\text { vs. Ag/AgCl }\end{array}$ \\
\hline WE-S0 & $-0.770 \pm 0.021$ \\
WE-S1 & $-0.780 \pm 0.009$ \\
WE-S2 & $-0.821 \pm 0.036$ \\
WE-S3 & $-0.836 \pm 0.012$ \\
\hline
\end{tabular}

Table 2 The onset potential of the oxidation current of the titania electrode before and after the sodium hydroxide treatment for 20 and $40 \mathrm{~min}$, then after lithium nitrate, sodium nitrate, or potassium nitrate treatment.

\begin{tabular}{cc}
\hline Electrode & $\begin{array}{c}\text { Onset Potential/ V } \\
\text { vs. Ag/AgCl }\end{array}$ \\
\hline Untreated & $-0.770 \pm 0.021$ \\
$20-$ min NaOH-treated & $-0.740 \pm 0.041$ \\
$40-$ min NaOH-treated & $-0.715 \pm 0.036$ \\
$\mathrm{LiNO}_{3}$-treated & $-0.774 \pm 0.015$ \\
$\mathrm{NaNO}_{3}$-treated & $-0.765 \pm 0.000$ \\
$\mathrm{KNO}_{3}$-treated & $-0.772 \pm 0.001$ \\
\hline
\end{tabular}


Table 3 Photoelectric conversion properties of the titania electrode (PE-S0) and the dye-dispersing titania electrodes (PE-S1, PE-S2, and PE-S3).

\begin{tabular}{ccccc}
\hline Electrode & $\mathrm{J}_{\mathrm{sc}} / \mu \mathrm{A} \mathrm{cm}^{-2}$ & $\mathrm{~V}_{\mathrm{oc}} / \mathrm{V}$ & $\mathrm{P}_{\max } / \mu \mathrm{W} \mathrm{cm}{ }^{-2}$ & $\begin{array}{c}\mathrm{FF} \\
\text { (fill factor) }\end{array}$ \\
\hline PE-S0 & $34.6 \pm 0.99$ & $0.40 \pm 0.01$ & $6.4 \pm 1.71$ & $0.46 \pm 0.11$ \\
PE-S1 & $5.56 \pm 0.73$ & $0.41 \pm 0.01$ & $1.2 \pm 0.03$ & $0.53 \pm 0.05$ \\
PE-S2 & $7.00 \pm 3.38$ & $0.45 \pm 0.03$ & $1.9 \pm 0.87$ & $0.61 \pm 0.08$ \\
PE-S3 & $39.8 \pm 9.41$ & $0.47 \pm 0.01$ & $7.6 \pm 0.92$ & $0.41 \pm 0.15$ \\
\hline
\end{tabular}




\section{Figure captions}

Figure 1 Oxidation current of the Photo-CV of the titania electrode (WE-S0) and the dye-dispersing titania electrodes (WE-S1, WE-S2, and WE-S3).

Figure 2 XRD patterns of the titania electrode (WE-S0) and the dye-dispersing titania electrodes (WE-S1, WE-S2, and WE-S3).

Figure 3 SEM images of the titania electrode (WE-S0) and the dye-dispersing titania electrodes (WE-S1, WE-S2, and WE-S3).

Figure 4 FTIR spectra of the titania electrode (WE-S0), the dye-dispersing titania electrodes (WE-S1 and WE-S3), and fluorescein powder.

Figure 5 FTIR spectra of WE-S0 (1) before and after sodium hydroxide treatment for (2) 20 and (3) $40 \mathrm{~min}$.

Figure 6 Oxidation current of the Photo-CV of the titania electrode (a) before and after sodium hydroxide treatment for 20 and $40 \mathrm{~min}$, then (b) after lithium nitrate, sodium nitrate, and potassium nitrate treatments for $40 \mathrm{~min}$.

Figure 7 (a) UV-vis and (b) FTIR spectra of the dye-dispersing titania electrodes (WE-S3) before and after the 120-min steam treatment.

Figure 8 Schematic diagram of the substitution of the dye molecules for the nitrate ions on the titania surface. 
Figure 9 Absorption spectra of the dye-dispersing titania electrodes (PE-S1, PE-S2, and PE-S3).

Figure $10 \mathrm{~J}-V$ curves of the titania electrode (PE-S0) and the dye-dispersing titania electrodes (PE-S1, PE-S2, and PE-S3). 
Figure 1

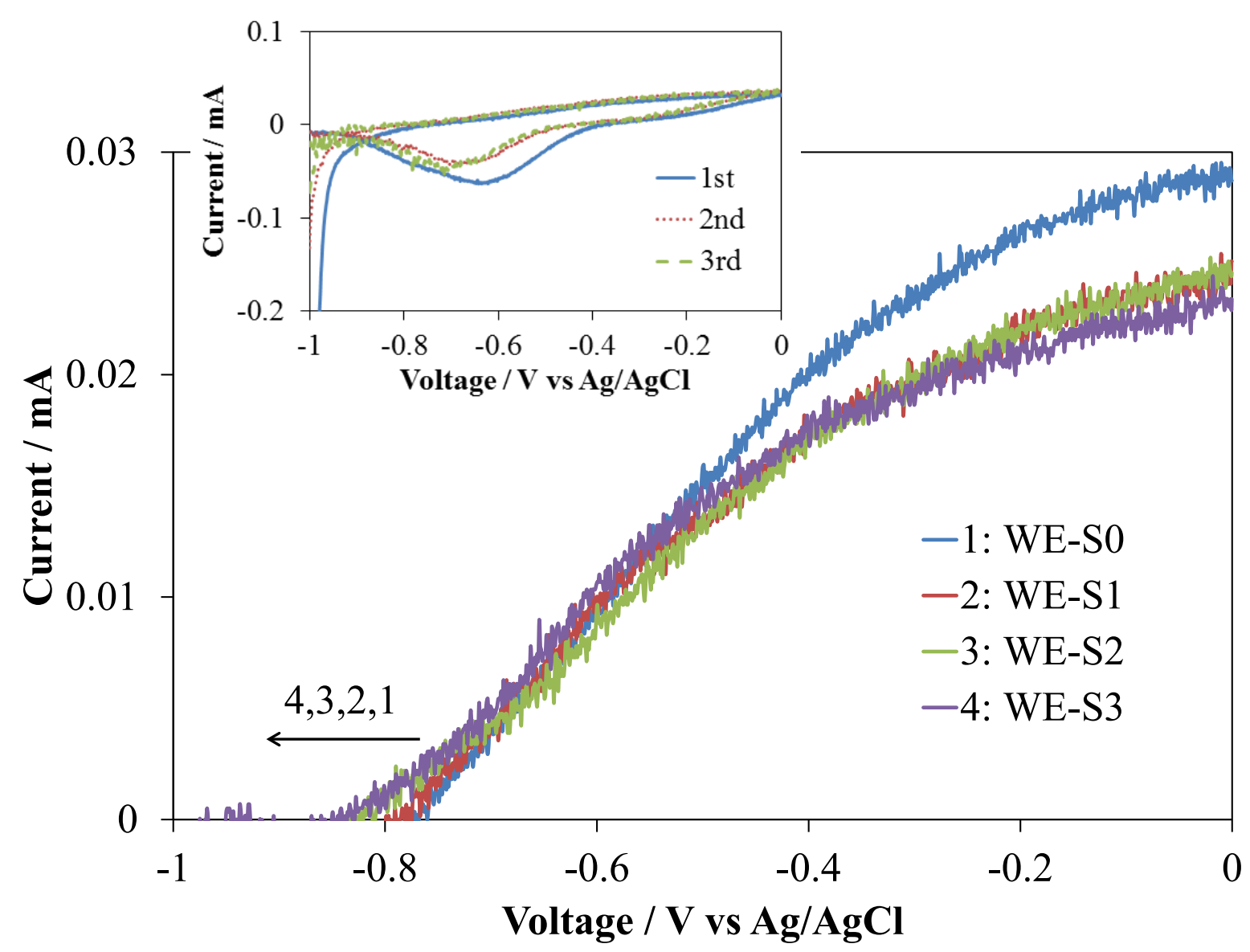


Figure 2

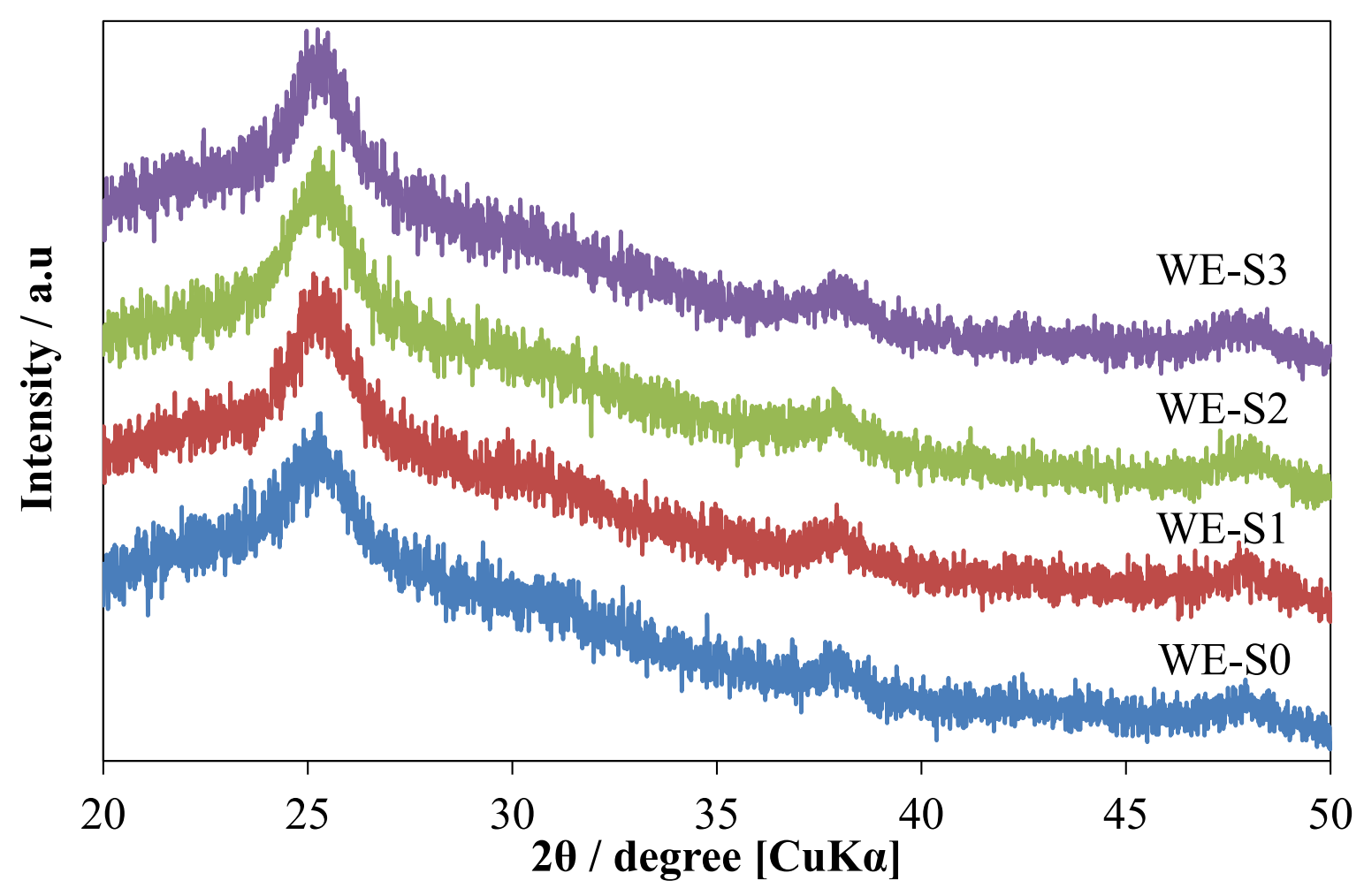


Figure 3
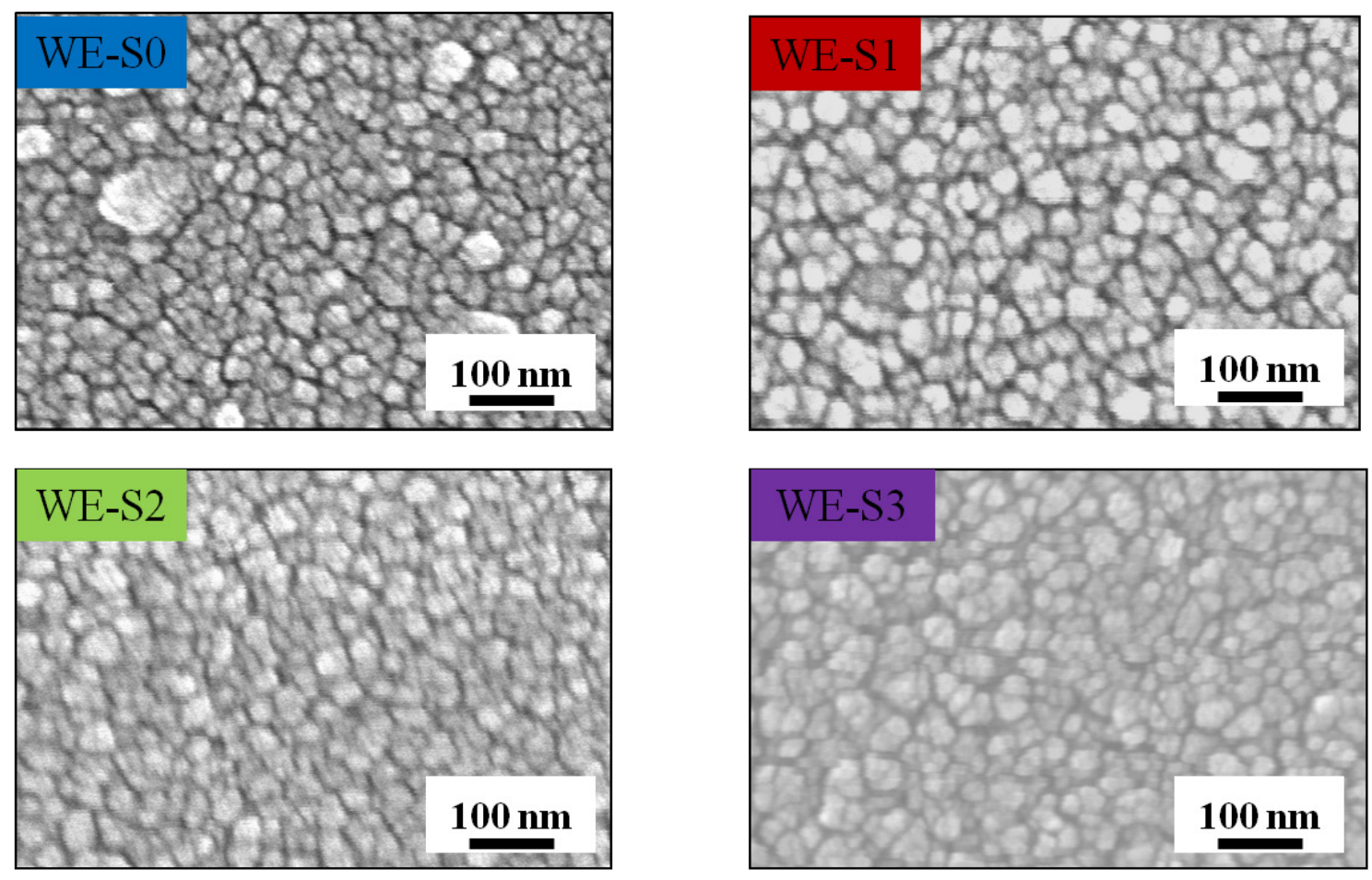


\section{Figure 4}

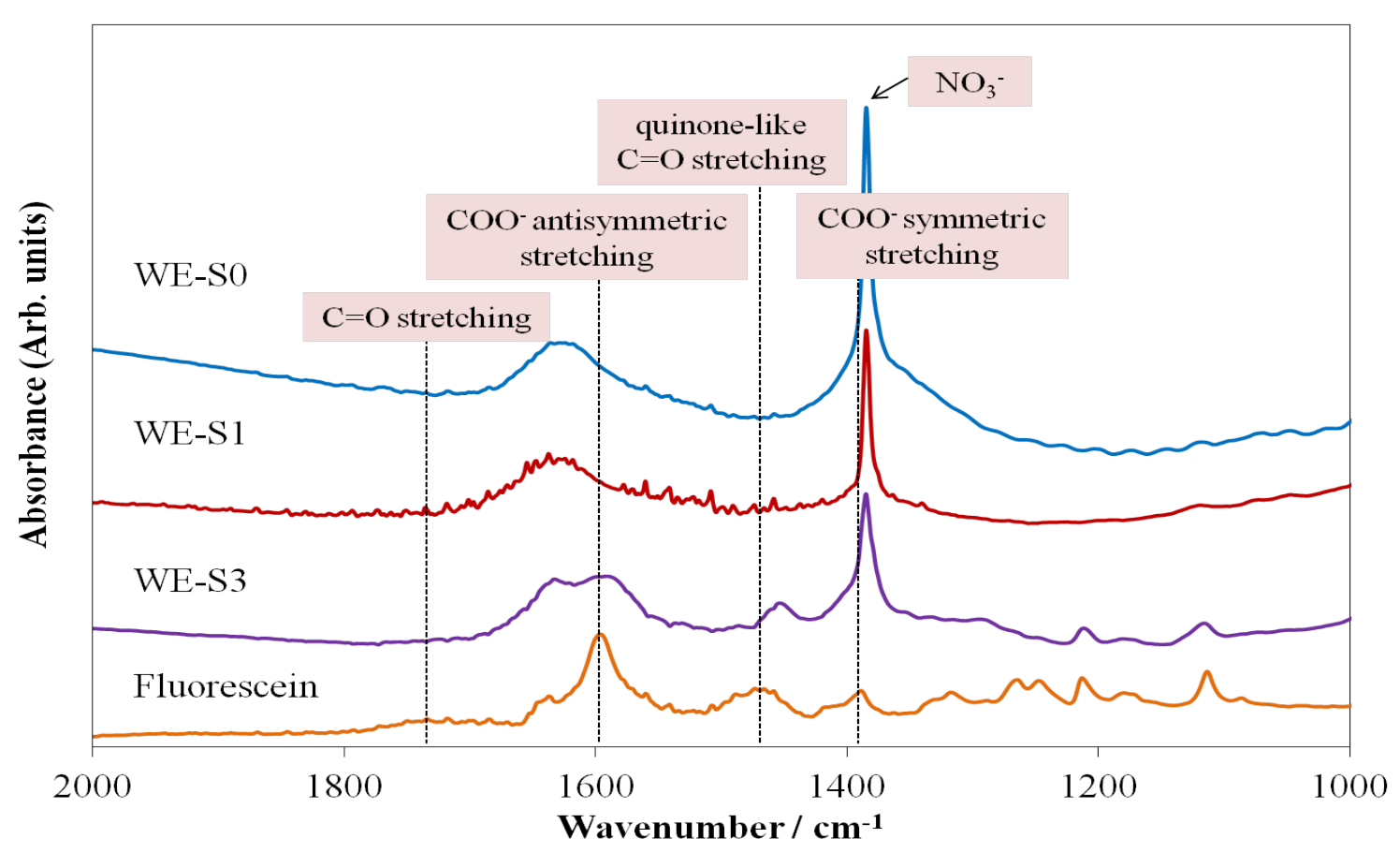


Figure 5

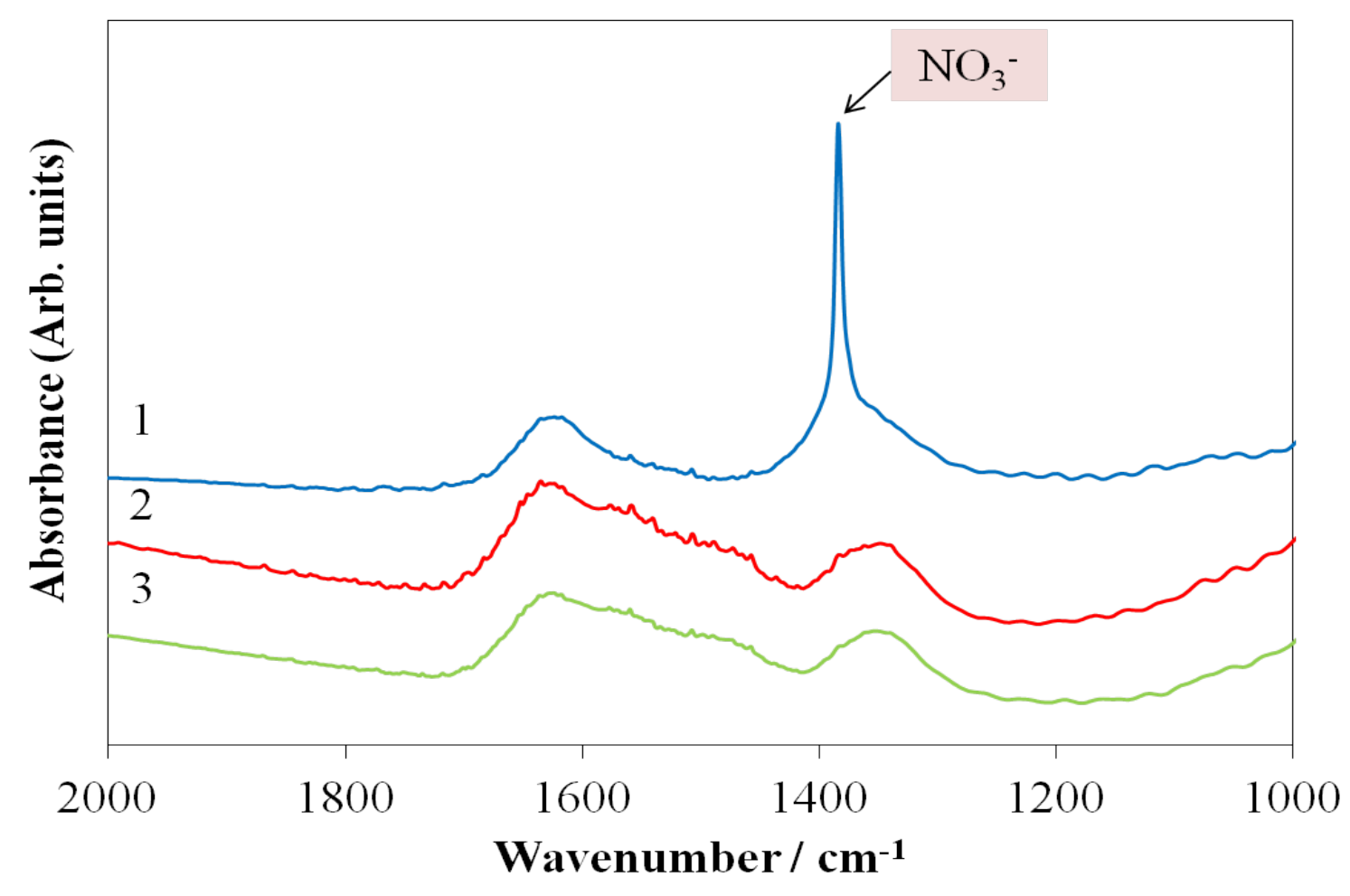


Figure 6

(a)

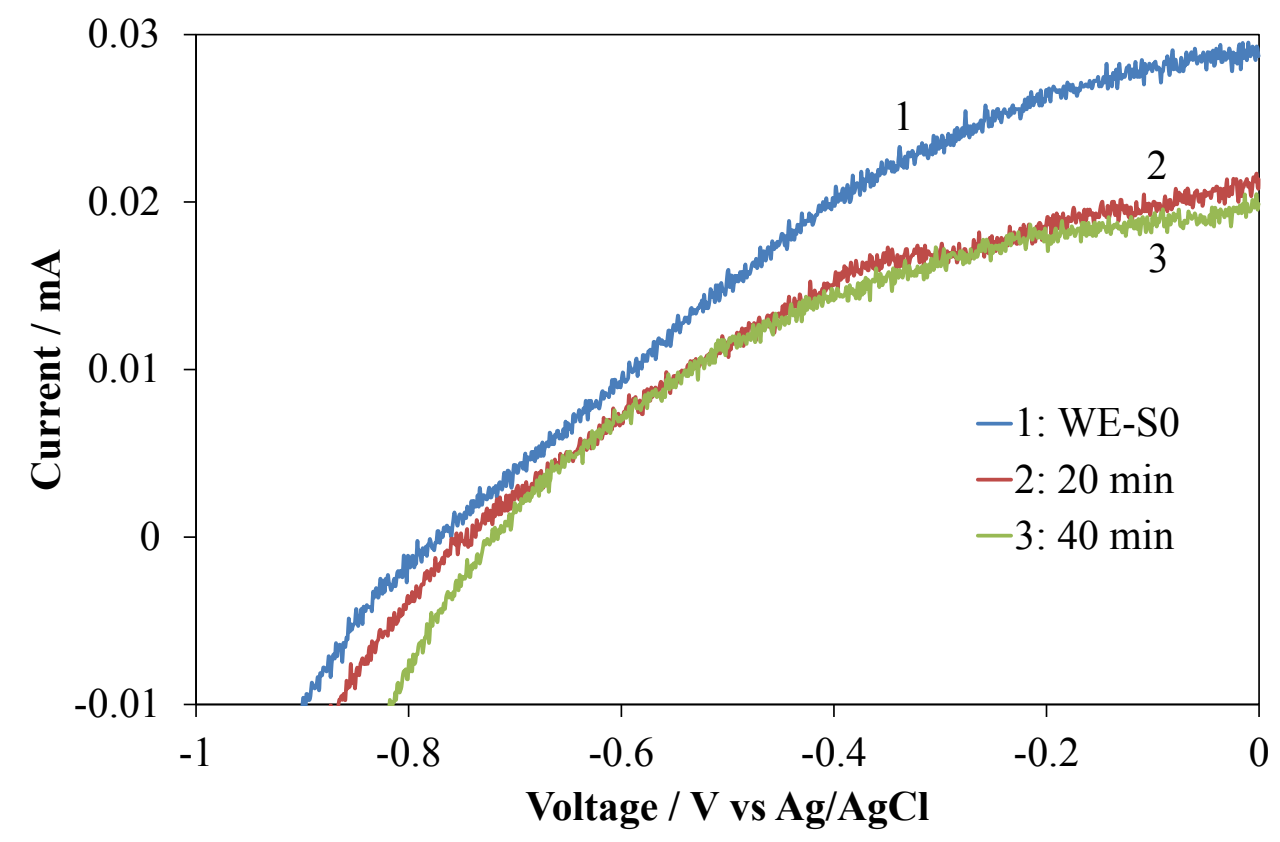

(b)

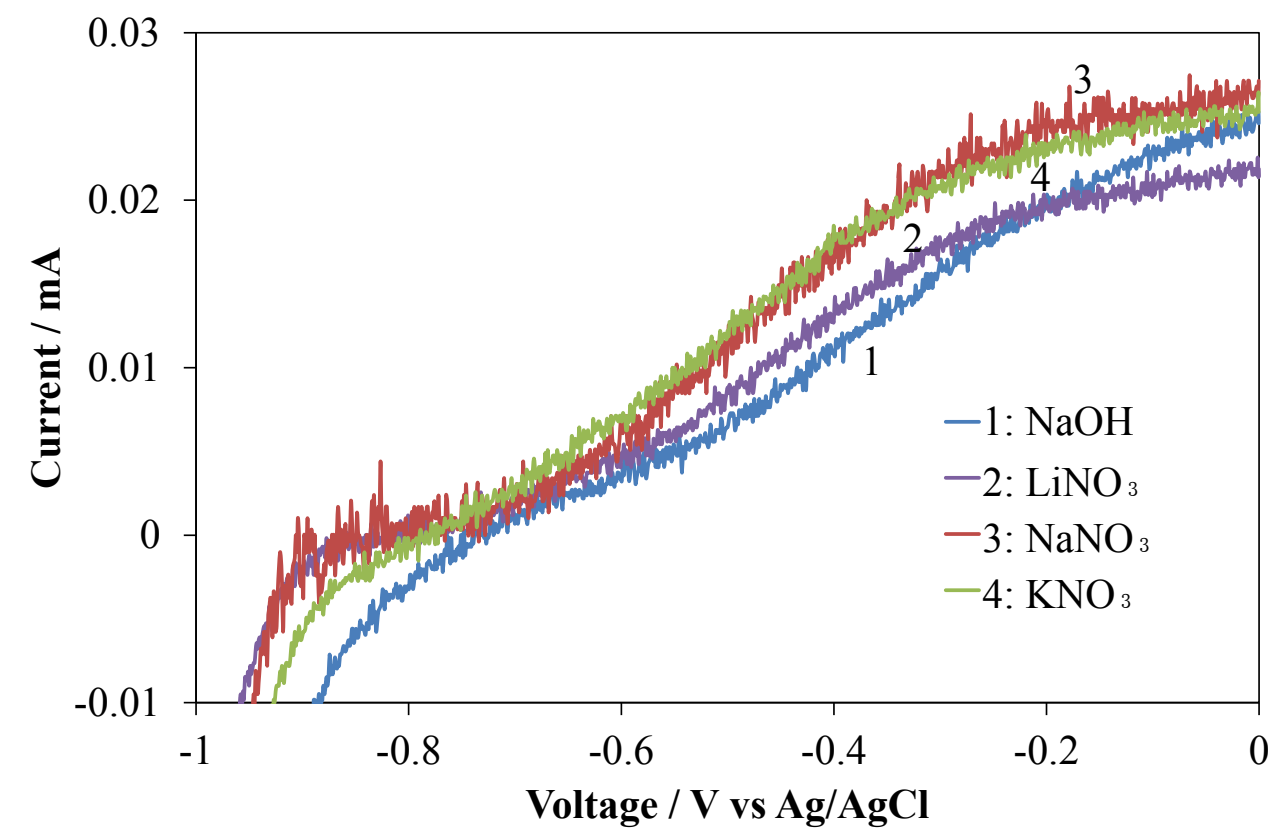




\section{Figure 7}

(a)

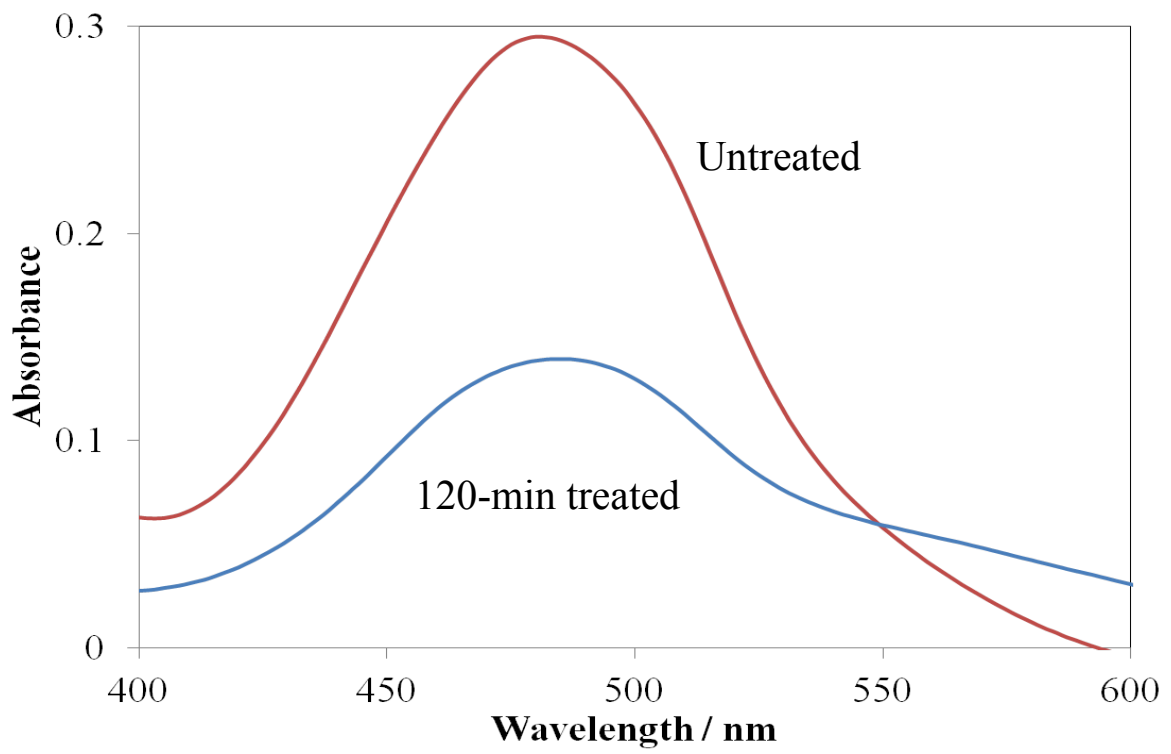

(b)

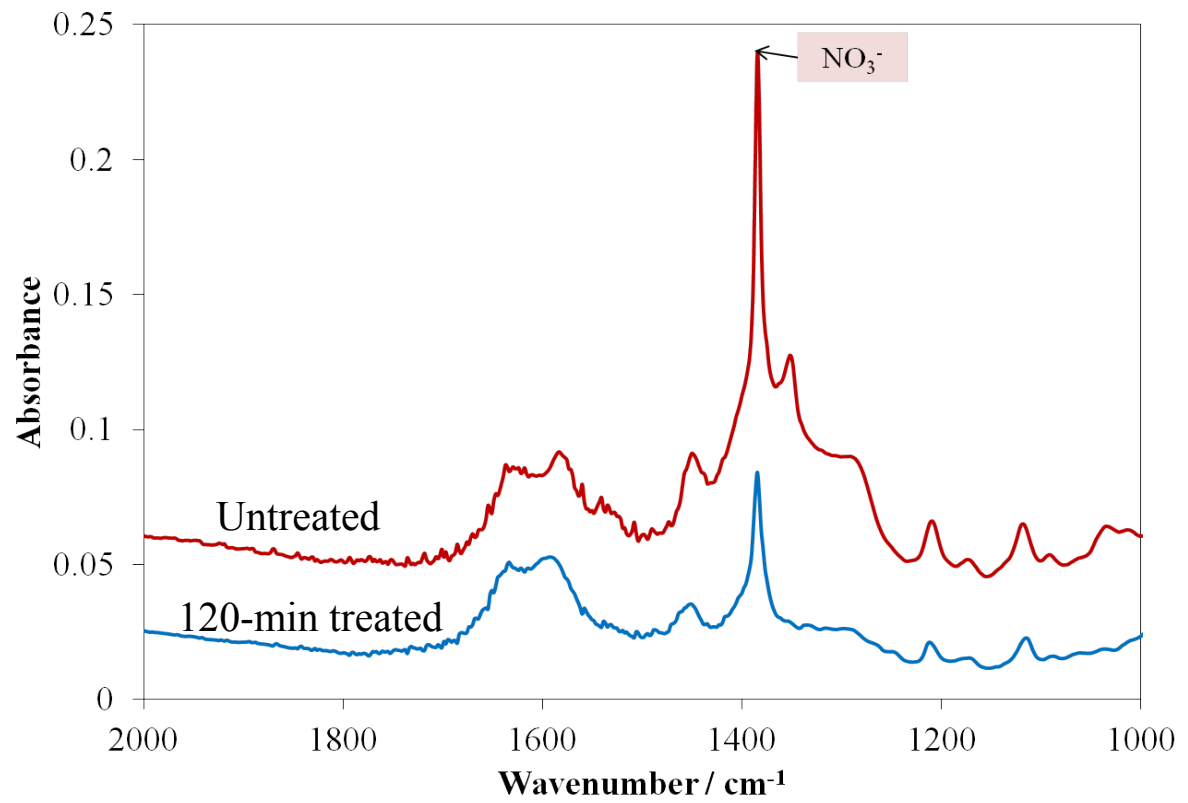


Figure 8
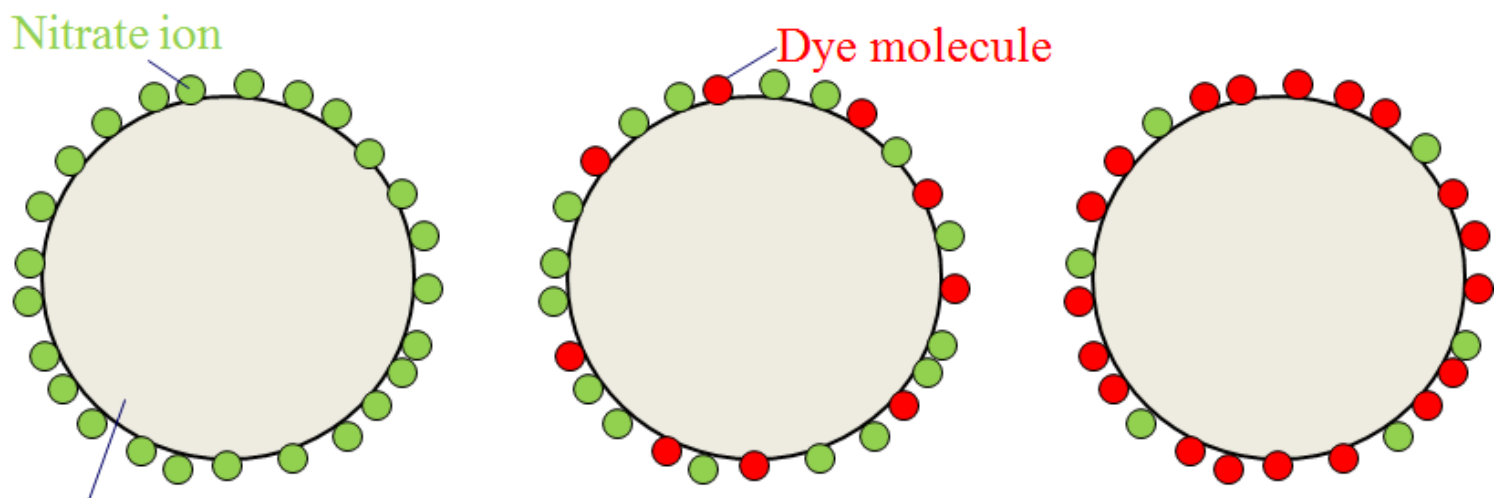

Titania

nanoparticle

Dye concentration

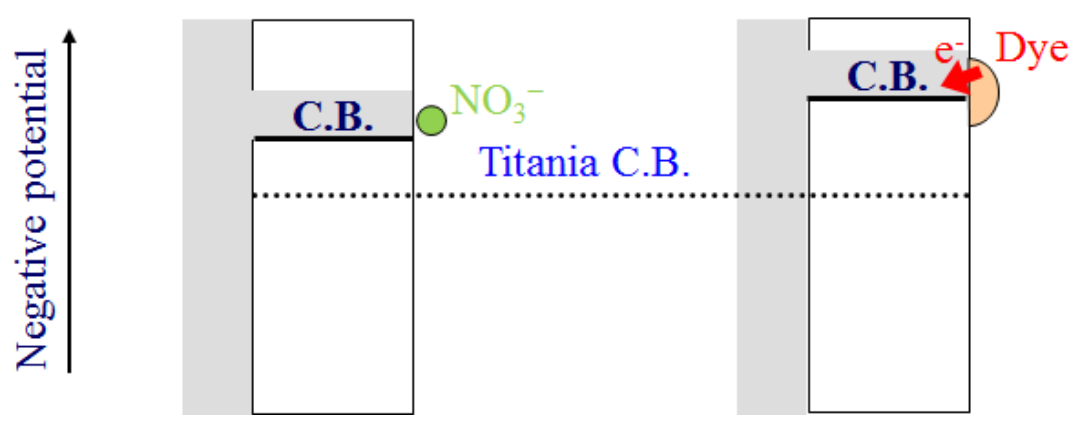


Figure 9

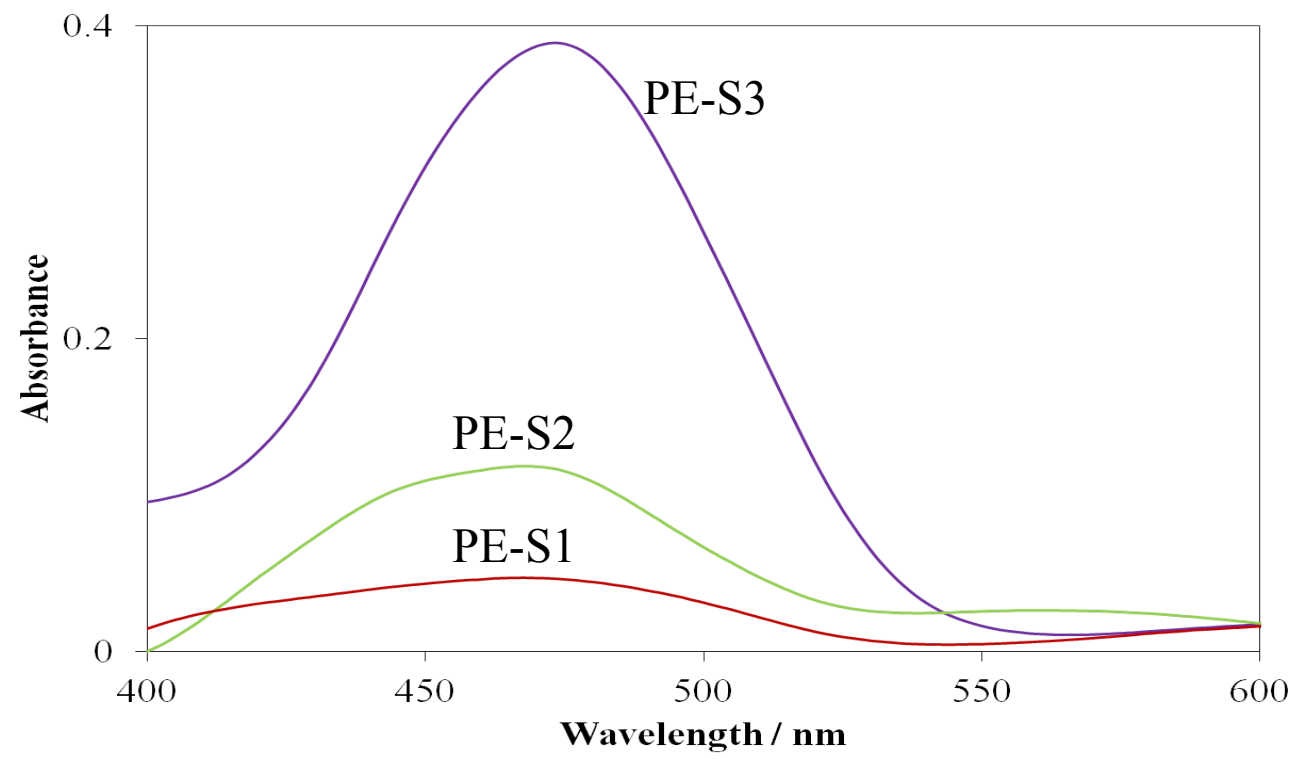


Figure 10

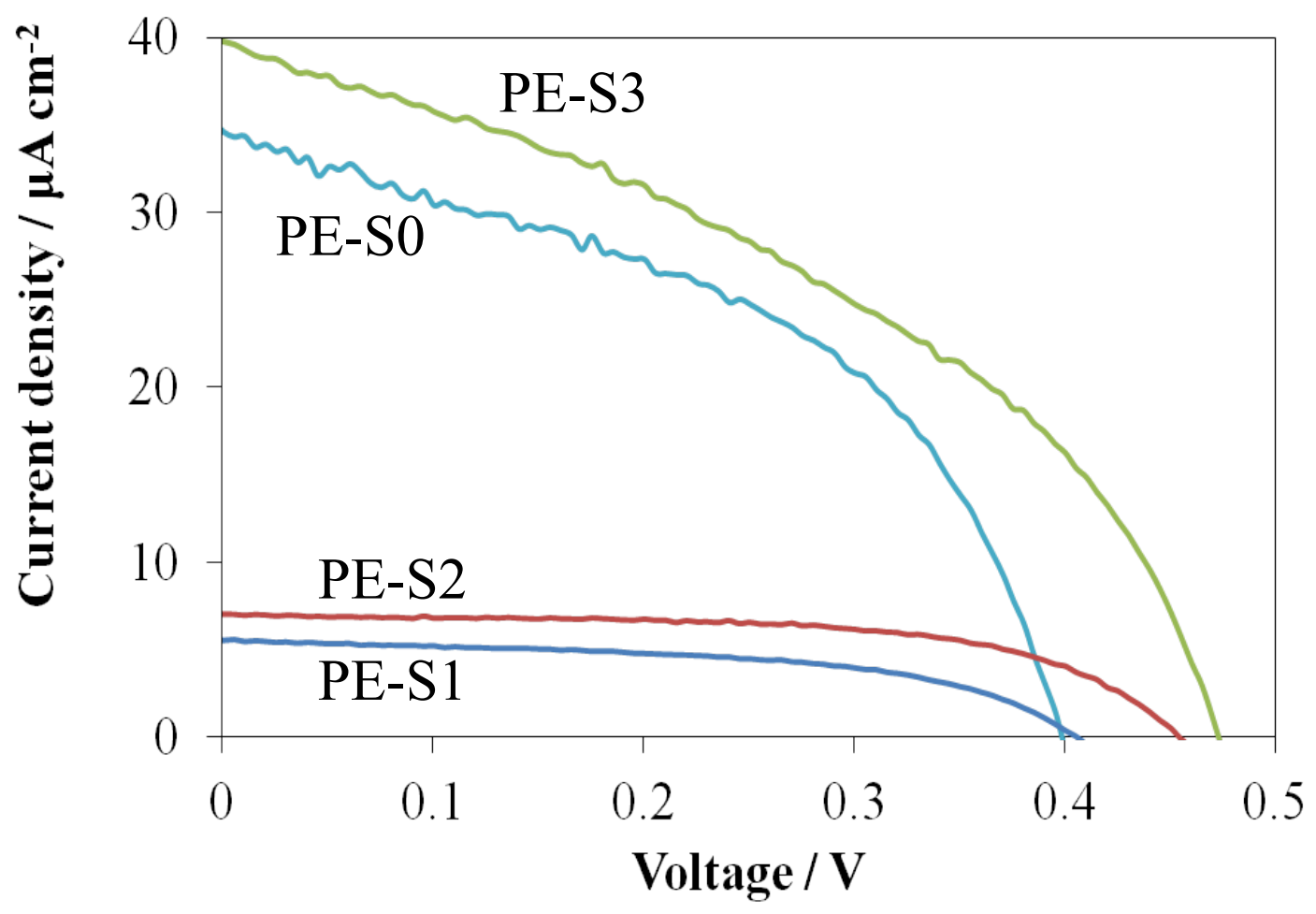

